\title{
The Origin of Art: An Approximation through Archaeological Evidences
}

\author{
Araceli Giménez Lorente \\ Department of Graphic Design, Higher Education School of Art and Design, (ISEACV), Spain
}

Received January 12, 2020; Revised March 2, 2020; Accepted March 12, 2020

Copyright $\bigcirc 2020$ by authors, all rights reserved. Authors agree that this article remains permanently open access under the terms of the Creative Commons Attribution License 4.0 International License

\begin{abstract}
A poetic idea is proposed, the origin of "aesthesis" is our origin. Art in its double side, as an 'object' and as a 'work', is as old as our human species. We could even say that it is the heritage of hominids, for each hominid species which were born in this planet with an antiquity known to be three million years old till our days. This implies hominid species discussed above, like Australopithecus africanus, Homo erectus, Homo heidelbergensis, Homo antecessor, Homo Neanderthal, and Cro-Magnon. In order to analyze the evolution of art from a new perspective, with archaeological evidence, the main methodology used is the observation and analysis of archaeological evidence, experimentation demonstrates the results. The most important result is the creation cladogram, in addition to an aesthetic theory, is a guide to classify archaeological evidence. Experimentation on archeology of fire values the Paleolithic civilization. All the archaeological evidence presented in this study will conclude that the first need as a species is aesthetics, and by evolution the art, and that the link is intrinsic to our human species. The main contribution to the field is a new perspective that links the evolution of our species with the origin and development of art. The novelty of this study is the multidisciplinary approach that includes the fields of aesthetics, cultural anthropology, archeology and the fine arts. The convergence of these disciplines concludes that art is intrinsic to the human species.
\end{abstract}

Keywords Aesthesis, Art, Human Species, Serendipity, Evolution, Creation, Archaeological Evidence

\section{Introduction}

This is the first aesthetic research based on archaeological evidence that demonstrates its evolution and its drift towards art. It involves the main human species, and the concept of aesthetics evolves as do the hominids.

To date, partial descriptions of the art of the Upper Paleolithic have been made, and some archaeological assessments are beginning to be made about recent paintings dated in the period Neanderthal, but no one had made an evolutionary line of the entire creative process so far.

We will begin this investigation with the creation cladogram that will be explained in more detail in the materials and methods section. It is the logical sequence of the study of the development of aesthetics in relation to Australopithecus africanus in its origin as a natural aesthetic object ( $\sim 3$ million years) until the creation of the work of art produced by Homo neanderthalensis ( 175,000 years).

The strictly necessary condition for the creation of this aesthetic theory is based on archaeological evidence; once these were found, and after analyzing other factors such as basic concepts of cultural anthropology, basic sociology, comparison with other animal species and even anatomical studies, conclusions were reached which resulted in this aesthetic analysis of the origin of art and its impact in our evolution as a species.

Another clarifying point that serves as an introduction is the creation of images accompanying the text, since using the original photos, scientific illustrations that are digital illustrations, when made from photographs, to give greater realism was not possible.

There are also photographs that record experiments and even infrared analog photographs, which have been recorded on a thermal infrared photosensitive reel, these are photographs by the author.

\section{Materials and Methods}

In this section we will present the aesthetic theory about the origin of art from the creation cladogram, and we will stop at each key point to explain it; see figure 1 . 


\section{CREATION CLADOGRAM}

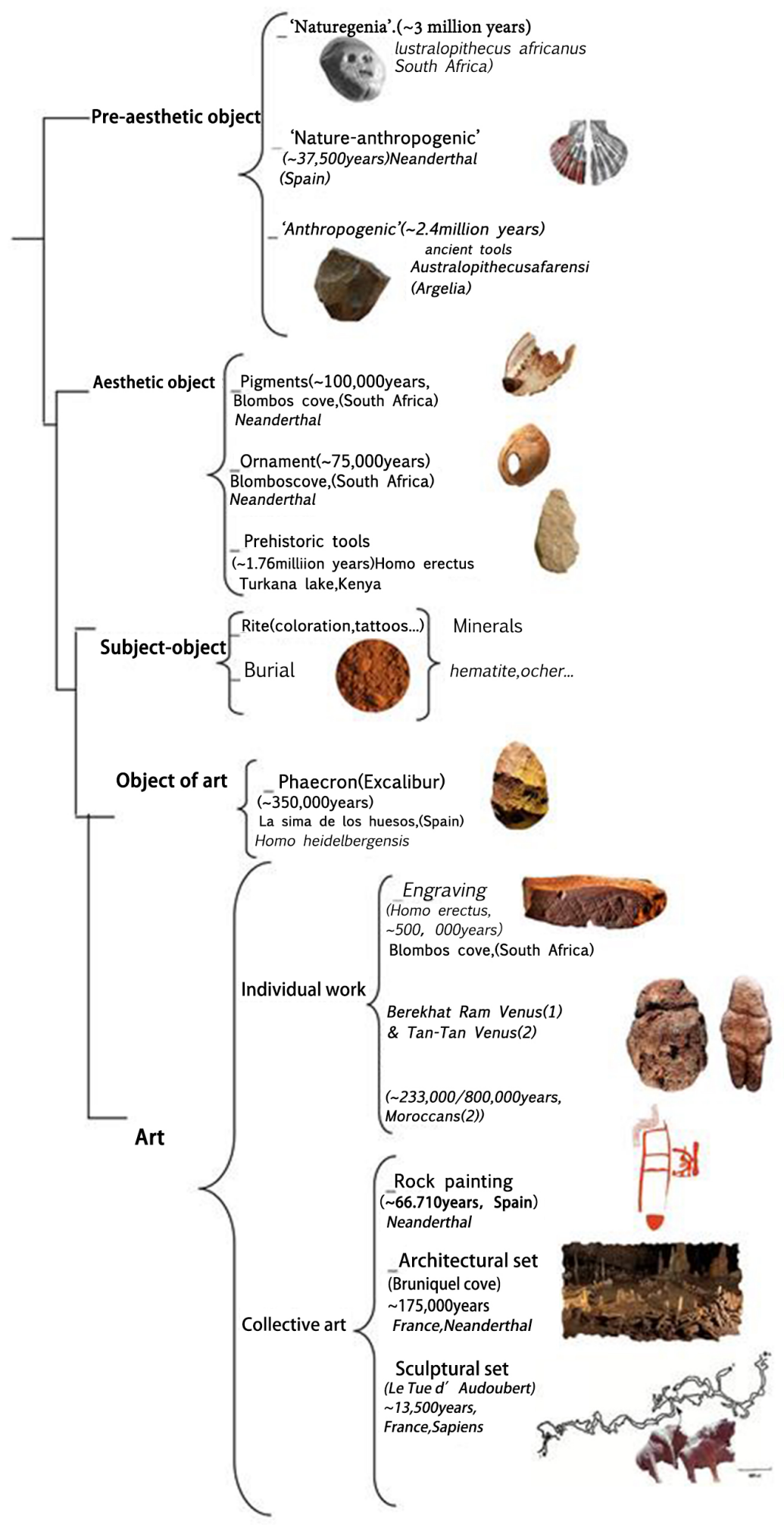

Figure 1. Creation Cladogram 


\subsection{Creation Cladogram}

We have an approach to the origin of the Art and its relationship with the theory of the first aesthetic. This summary explains the evolution from the aesthetic concept to the first work of art. [1]

In 1925 the archaeologist Raimon Dart discovered the call Makapansgat Pebble, it is a river pebble from Sterfontein (South Africa), of small dimensions, $8.3 \mathrm{~cm}$ and 250 grams, dated approximately in 3 million years; this small stone was found in a habitat, cave where our ancestors lived, Australopithecus africanus; see figure 2. It was studied by the anthropologist Robert G. Bednarik in the decade of the 90s, but until December 1999 it was not published by the National Geographic Society.

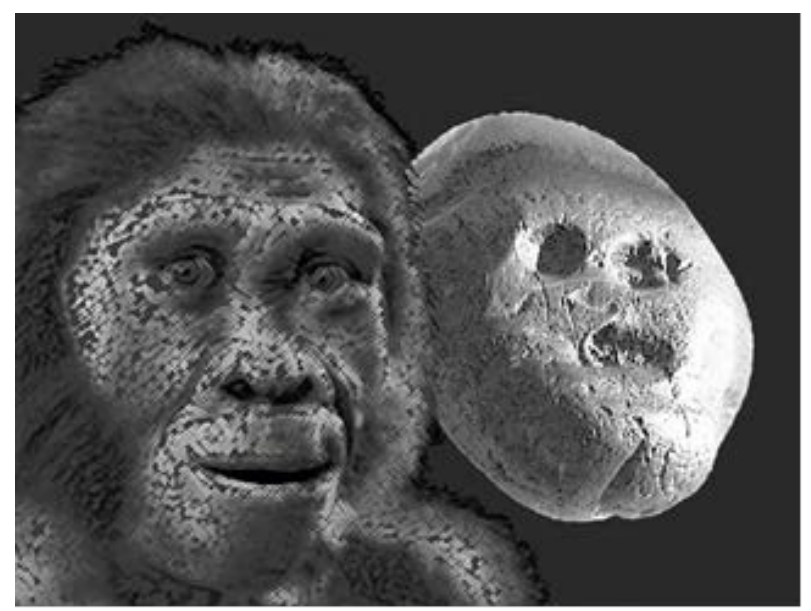

Figure 2. Australopithecus africanus and Makapansgat Pebble

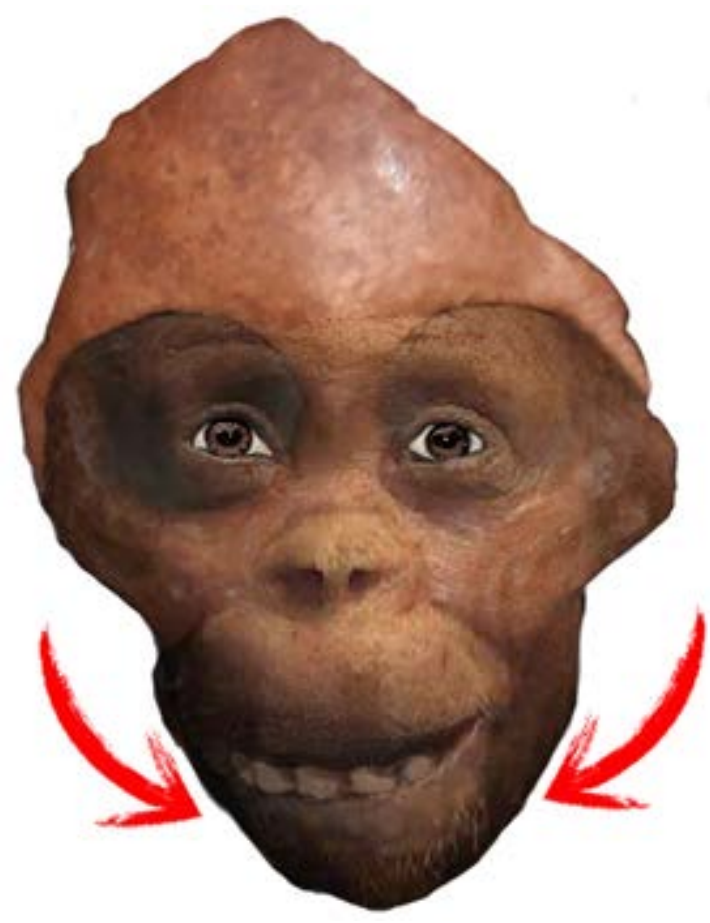

Figure 3. The zygomaticus major muscle in the child of Taung
This would be to date the first pre-aesthetic object 'of natural origin' or naturegenic ${ }^{1}$ found, a serendipity, something casual formed by the erosion of the river water on the stone that has an only shape, a shape that we recognize as a human face, and that our ancestors may have also interpreted in the same way.

Three million years ago, this hominid species did not use tools, or dress or fire, but an individual, perhaps a child, could recognize a face with human traces, which would cause an emotion because it took the pebble into their habitat and they kept it. As the feelings do not fossilize, we can only study the facial anatomy of this hominid to know if they could laugh, or cry... the zygomaticus bone is the base of the zygomaticus major muscle and the risorius of Santorini, which are necessary to smile, that is, the Australopithecus africanus could laugh; see figure 3.

An impact made by Makapansgat Pebble on the Australopithecus africanus clan is evident because it was conserved and found inside the cave that it inhabited.

A sociological meaning of the stone to the inhabitants the Australopithecus species, in terms of sociology, according to Elias Canetti, the person is a 'mass crystal', capable of influencing another 'crystal' and by the phenomenon of 'multiplication' is it expands the entire mass, since this pre-aesthetic object had not been assumed by the clan, the clan would not have retained it. [2]

In animal ethology there is also an aesthetic learning, there is a bird in Australia and in New Guinea, called Ptilonorhynchidae (Bowerbirds) or the bird architect, who has an innate 'pre-aesthetic' behavior that develops throughout his life.

Bowerbirds have striking nests; the birds create their nests as a work of architecture. The Bowerbirds bring to its nest bones, small branches, feathers, snails, flowers and other natural or artificial objects such as bottle caps. It groups them by color and shape forming a carpet, before he has built a semicircular arch with small branches or a cave, and once finished his work awaits the female bird who will choose that nest or another by their criteria.

Although there are animals with an undeniable aesthetic sense, only a hominid would be able to recognize a human face in a river stone, and its conservation by the clan as the first aesthetic learning is the beginning of our appreciation of art form.

The definition of a Nature-anthropogenic ${ }^{2}$ in relation to the concept of pre-aesthetic object is evidenced in a seashell shows a minimal manipulation.

A Nature-anthropogenic object is artistic form found in a natural object. Konrad Lorenz, terms this as imprint created on a naturopathic object, where an innate creates a learning process.

It could be understood that within this 'first aesthetic'

1 Self-coined term, a natural object with aesthetic character originated by nature, through erosion or other natural causes.

2 Self-coined term is the minimum human intervention on a natura aesthetic object. 
the Innate Trigger Mechanism act, which in ethology is a physiological machinery that filters and is a stimulus that reaches the organism from the outside world.

The 'neophilia', is the first stimulant, the one that initiates the creative process, and 'the imagination' which orders an order of priorities related to the sum of psychoperceptions and psychoemotions, this is a mental process that needs biodynamics enable to the act. The first archaeological evidence related to Neanderthals, is a seashell with red pigment called hematite, the pre-aesthetic object has two circular holes on both sides; see figure 4 .

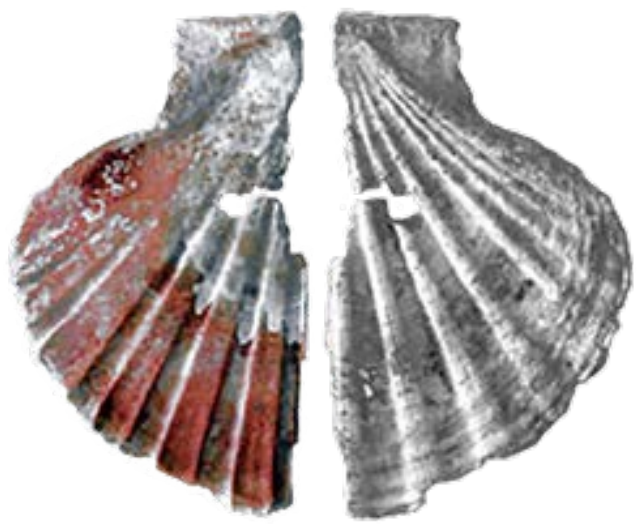

Figure 4. Pre-aesthetic object. Neanderthal

The next phase in creation is the development found in an anthropogenic object. Fig.4 as an individual work, there are two archaeological evidences, the Tan-Tan Venus and the Berekhat Ram Venus.

If we look at the two Venus in figure 5, we see convergences and divergences between them. First, both dates are similar, also their ambiguity, each one has a maximum and minimum dating of 800,000-500,000 and 300,000 years old. There is some doubt about if the human species made the Venus. Scientific studies by Francesco d'Errico and April Nowell [3] in relation to the Berekhat Ram Venus as well as, others Robert Bednarik [4] on the Tan-Tan Venus, defend the artistic intentionality of the statuettes.
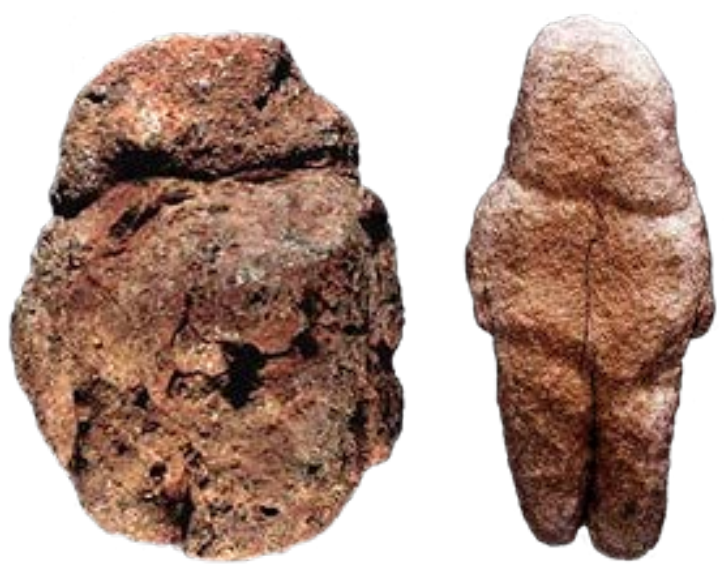

Figure 5. "Nature-anthropogenic” object. Neanderthal vs Homo erectus
The site of the Berekhat Ram Venus was between two basaltic layers which have been dated between $800,000-233,000$ years old; if this sculpture found on the edge of the crater of an extinct volcano using maximum dating, the author believes it made by the Neanderthal species, but if it is of the maximum dating it would be made by Homo Erectus. The dimensions of this Venus are approximately $3.50 \mathrm{~cm}$ high, $2.50 \mathrm{~cm}$ wide and $2.10 \mathrm{~cm}$ thick, and weighs $10.33 \mathrm{~g}$. Microscopic analysis by Alexander Marshack has made it clear that ancient hominids were responsible. The material is a piece of tuff. the hardness on the Mohs scale of that of the tuff is the same as that of limestone at level 3. Professor Naama Goren-Inbar of the Hebrew University of Jerusalem discovered the statuette in 1981.

The Tan-Tan Venus, anthropomorphic figure was found in sediment dated between 300,000 and 500,000 years old. The material of this Venus is metamorphosed quartzite. Its approximate measurements are $5.82 \mathrm{~cm}$ long, $2.64 \mathrm{~cm}$ wide and $1.20 \mathrm{~cm}$ thick and it weighs approximately $10 \mathrm{~g}$. These are very similar measures to those of the Venus. The material hardness is 7 on the Mohs scale. It was discovered by the German archaeologist Lutz Fiedler in the Draa river basin in Tan-Tan, northern Morocco in 1999.

After studying these two archeological evidences and respective scientific analysis, it follows that the first sculpture found, are two Nature-anthropogenic objects, a natural object with a given shape and that with minimum human intervention became two sculptures. The difference in figure 3 , is that the two Venus follow the same creative process: find a beautiful object in nature and with minimal intervention give it cultural character, in the sea shell it is a pre-aesthetic object and in Venus they are works of art, sculptures; see figure 5.

Following the cladogram showing the development aesthetic creation, we have a third step the anthropogenic object. At this time hominids, Australopithecus afarensis or Homo antecessor created a tool from stone raw material.

The main difference between the $\mathrm{A}$. afarensis and $\mathrm{H}$. antecessor artifacts is the purpose, while what in the first case makes approximately $\sim 2.4$ million of years, as an ancient tool, in the second case it is a symbol, called Phaecron $^{3}$ (Excalibur) , 350,000 years ago, found in a collective burial.

The engraving found in Blombos cave was made by Homo erectus, dated in $\sim 500,000$ years ago, it is a palimpsest with geometric notations, in the form of linked rhombuses, or perhaps they are diagonally oriented to the right and others in the opposite direction, they may mean a Small time intervals, such as days. The interpretation of

3 It is the definition of objects of between 500,000 and 400,000 years belonging to Homo heidelbergensi and the predecessor that apparently are hand axes, but have a symbolic function 
this archeological evidence will not be commented on because it does not have more information to avoid speculation.

Two colors appear in figure 6 that correspond to different strokes in different periods, you can know by the "calligraphy" of the stroke and by its depth, there are at least two authors, being represented by the gray color the first author and the author more recent with the color red, since that path is above.

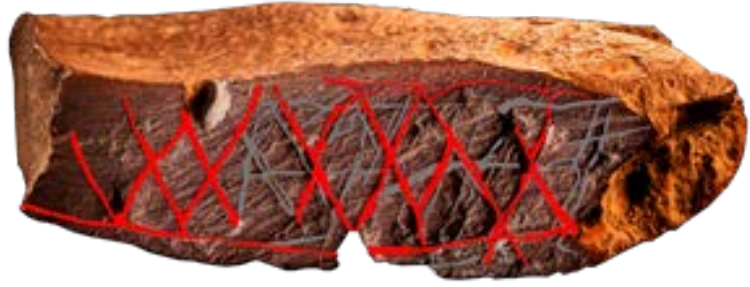

Figure 6. Blombos engraving. Palimpsest by Homo erectus

All the above mentioned correspond to Pre-aesthetic object, Aesthetic object, Subject-object and Object of art, but to get to the concept of artwork you must go one step further.

The definition of art includes Individual work and Collective art, in the first case we have the Venus and the cave paintings and engravings, while in the second case they are works such as the palimpsest and the sculptural and architectural sets. In the "Creation Cladogram" you can see two examples of two collective works, dated in $\sim 175,000$ years ago, it is an Architectural set found in Bruniquel cove made by Neanderthals, the second case is a Sculptural set dated in $~ 13,500$ years ago by Sapiens, they are the two oldest cases published to date.

The symbolism in Neanderthal art deserves a particular study, especially in two cases, figures 5 and 7.

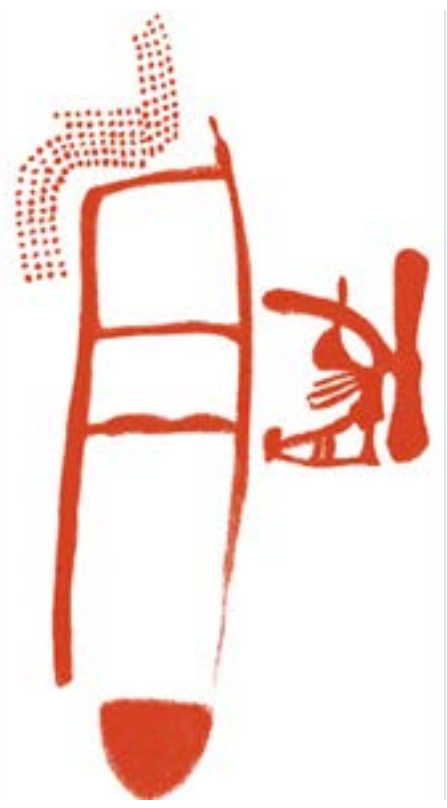

Figure 7. Enigma of Pasiega. Rock painting by Neanderthal
The uniqueness of Neanderthal painting called Enigma of Pasiega is the synthesis of the image. A synthetic image is an advanced concept from an artistic point of view. Therefore, it is not possible that it is the first Neanderthal artistic representation, the first work should be more realistic, a copying nature, and not an interpreting or making it a symbol, an ideogram such as this case. In figure 7 we can see the complexity of the image, they seem to be at least 4 signs, the points, the inverted triangle, the rectangle with divisions and the anthropomorphic figure.

Without further evidence, we cannot speculate on the meaning of the painting, but we can say that there is a regular pattern, in the matrix of points where we can count the following sequences: $(12,12,11,11),(20,21,22,23)$, $(9,8)$, in figure 7 , counting from right to left, first the column, then the curve and the last set would correspond to two horizontal lines on the curve. This pattern cannot be casual; the next evidence is expected to clarify this mysterious Neanderthal image. [5]

An annotation is that in figure 7 the two images of two deer have been omitted, from inside the rectangular construction, considering them later, and by style attributed to modern Homo Sapiens, that is, to the Upper Paleolithic, that means, the painting is a palimpsest.

Other archaeological evidence worthy of comment within the creation cladogram is a Neanderthal architectural ensemble in Bruniquel cave, figure 8. At 300 meters from the entrance of the cave there is a construction that we know by Neanderthal dating. In figure 8, 400 intentionally broken stalagmites are grouped and arranged in six structures, of these structures the two largest are rings and measure $6.70 \times 4.50 \mathrm{~m}$, and $2.20 \mathrm{x}$ $2.10 \mathrm{~m}$ respectively in a gallery of a maximum of $20 \mathrm{~m}$ long, and with a clay soil. The dating of this site is by the uranium-thorium method for dating stalagmites, and when these were intentionally cut to be organized in circular structures. [6]

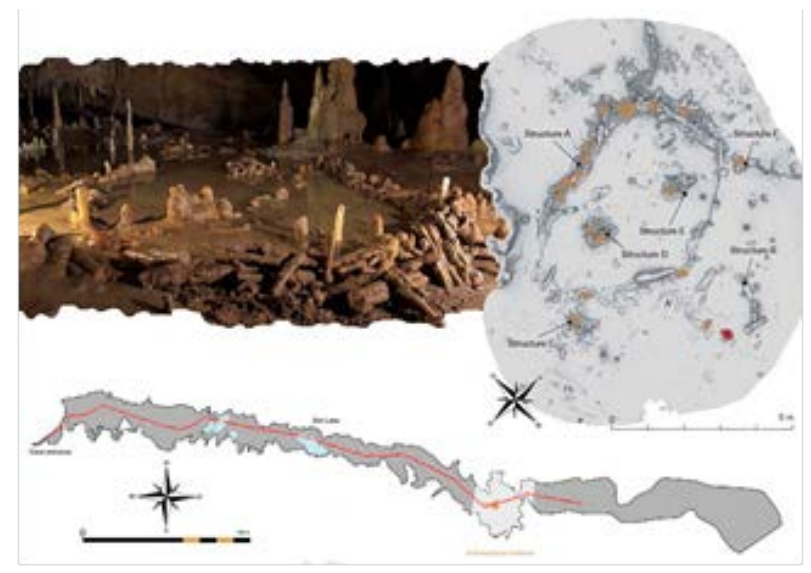

Figure 8. Architectural set by Neanderthal

It is evident that the intentionality of this archaeological structure is symbolic; it is a place without natural lighting, which depended on bonfires created by the Neanderthals. 
It is also evidence of aesthetic work, in the beauty circular structures.

The archaeological ensembles by Neanderthals produced the sculptural ensembles at Le Tuc d'Audoubert. This is a set of two finished paleo-sculptures, the third in process and the fourth drawn on the ground, located in a circular instance of a blind cavity 700 meters from the entrance of the cave of Le Tuc d'Audoubert in Montesquieu-Avantès (Ariège, France), and oriented towards the southeast polar in cron of polarity Brunhes (normal). They wen discovered, October 10, 1912 by Max Jacques and Louis Begouën: the discovery was made public and sent to the prehistorian Emile Cartailhac by Count Begouën (Professor of Paleontology at the University of Tolouse): "The Magdalenians also modeled clay". 9.

They did not model the clay, they carved it; see figure

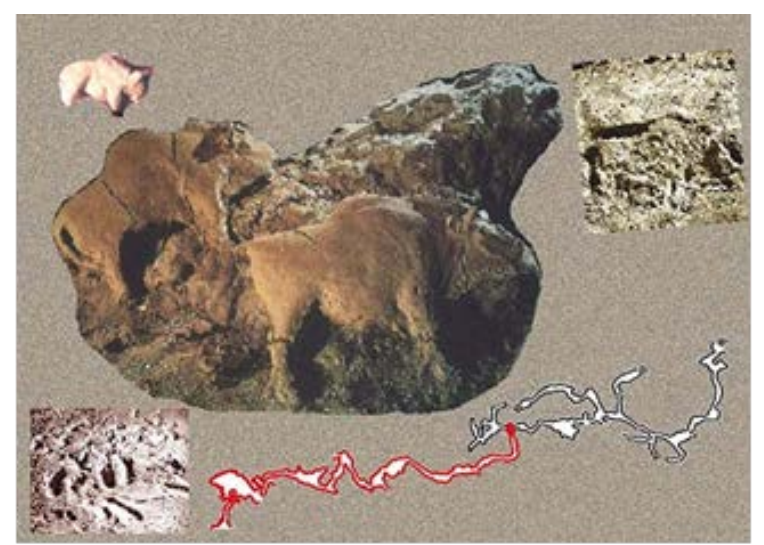

Figure 9. Sculptural set by Cro-Magnons

The Volp river that crosses the cave has deposited clay during a geological time and impregnated the entire blind cavity. When the temperature drops and the river water drops, the clay of the upper part solidifies to create a block of solid clay, this block is the one used to carve the bison. Being the clay floor, there are printed human footprints (heels) and the handprint of one hand.

In the two bison there are wounds of flint tips, they would surely be spears of wood and stone point, it is possible that with a symbolic intentionality the sapiens will throw spears against the sculptures, the bison are represented standing and not dejected. There would be three groups, the artists, the public and a mixed third party that would join the first two groups, these would probably throw the spears and dance.

In summary we have a clear evolution that is evident with the cladogram of creation, sufficiently defended in this section.

\section{Results}

Due to the presence of several sculptural ensembles found in blind cavities where natural light does not enter like Le Tuc d'Audoubert or Bruniquel cove, and by extension to the rest of the caves, and the non-evidence of smoke in the caves, we can talk about technology of the fire, and the lighting that did not cause smoke. Fuel was animal fat, from the marrow.

The blind cavity of the cave studied in the sculptural ensemble by Cro-Mangons needed to be illuminated, however there are no smoke traces on the walls, a different illumination was needed, the marrow lamps that we know are at least dated to the upper paleolithic.

Making the fire in the Upper Paleolithic, was replicated in a Fire Archeology Workshop (UV), held during the doctoral courses stage (fig.10), [7].

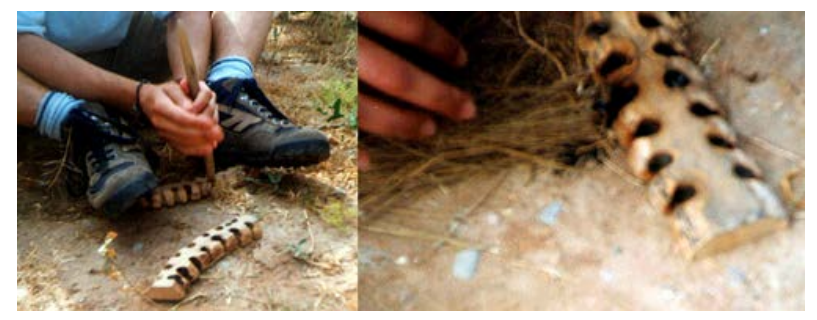

Figure 10. Experimentation on archeology of fire. Paleolithic lamps

This included reproducing the paleolithic lamps with animal fuel grease, marrow (figure 11).

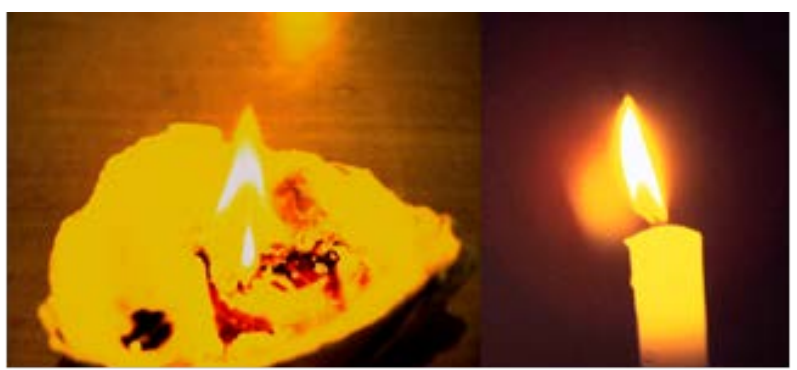

Figure 11. Infrared photography of a paleolithic lamp compared to a paraffin candle

This study contrasted it with a type of current lighting based on fire, in a comparative study were made with a paraffin candle and recorded with infrared photography.

The analog camera that was used was a Pentax MZ-30 and the Sigma $\varnothing 55 \mathrm{~mm}$ lens with $28-80 \mathrm{~mm}$ macro zoom, an orange filter is added to increase the contrast and for greater definition. A 55mm infrared color film was used to photograph the fire, since we want to know the heat quality it presents compared to other fires. The infrared channel captures a light spectrum not visible to the human eye, between 700 and 1200 nanometers. The visible light in the paleolithic lamp is lower compared to the paraffin candle, but in the IR spectrum the Magdalenian lighting is more intense.

For laboratory results on paleolithic lamps, the light has been measured with a luxmeter, called Sekonic Handy Analog Lumi, with two scales corresponding to two 
sensors, the first goes from 0-5000 luxus, distributed $[1000,2000,3000,4000,5000]$, where each division is 100 luxus; We have a perforated filter that allows us to multiply our x10 scale. The second scale that we find below in red to differentiate it from the one above ranges from 0-1000 luxus, distributed as follows: [0, 200, 400, $600,800,1000]$, and here each division of the scale It is 20 luxus. To measure the light of the paleolithic lamps and in comparison, to that of the paraffin candle, the lower red scale has been used, which is the one with the least power.

The measurements were taken for 120 minutes in a 5-minute interval, first of the paleolithic lamp and then of the paraffin candle, so the independent graphs were made and then the comparative one.

The graphs show greater stability in the paleolithic lamp, the trend line is more horizontal in relation to that of the paraffin candle, which indicates that the fuel is more stable, and wears out constantly.

As for the arithmetic means we have rounding mean $_{\mathrm{y} 1}=152.17 \mathrm{~lx}$, mean $_{\mathrm{y} 2}=366.96 \mathrm{~lx}$.

The paleolithic lamp is clearly of less intensity, but this has an advantage, since the lower energy consumption consumes less oxygen.

\section{Paleolithic Lamp}

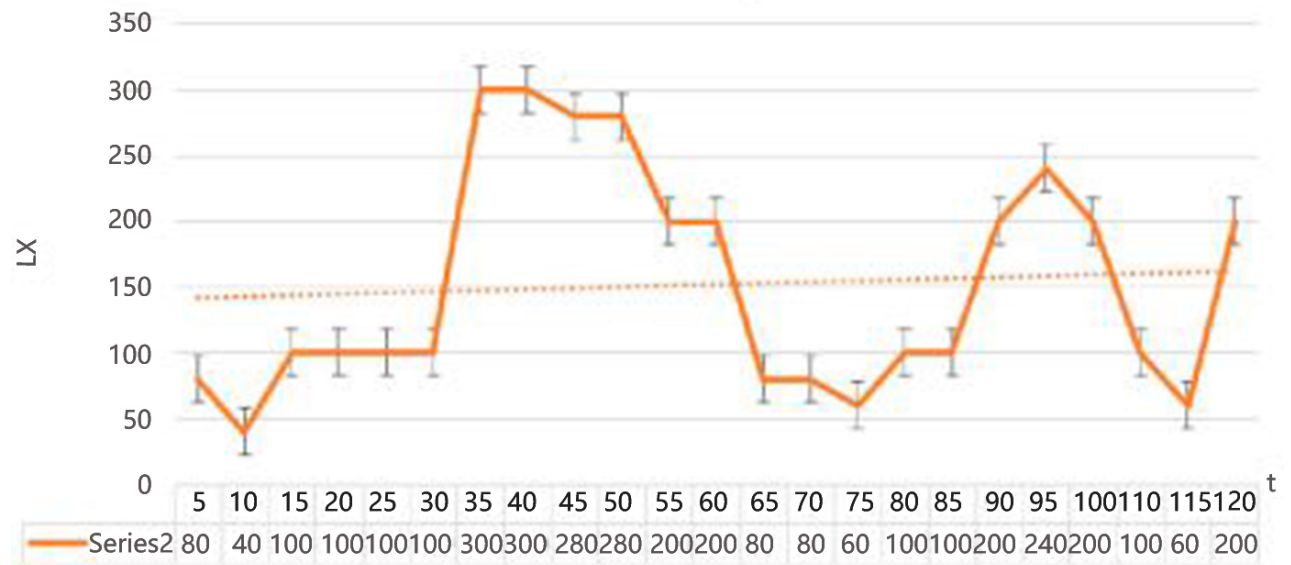

Series2 $\ldots . . . \cdots$ Lineal(Series2)

Figure 12. Paleolithic Lamp (Graph)

\section{Paraffin Candle}

600

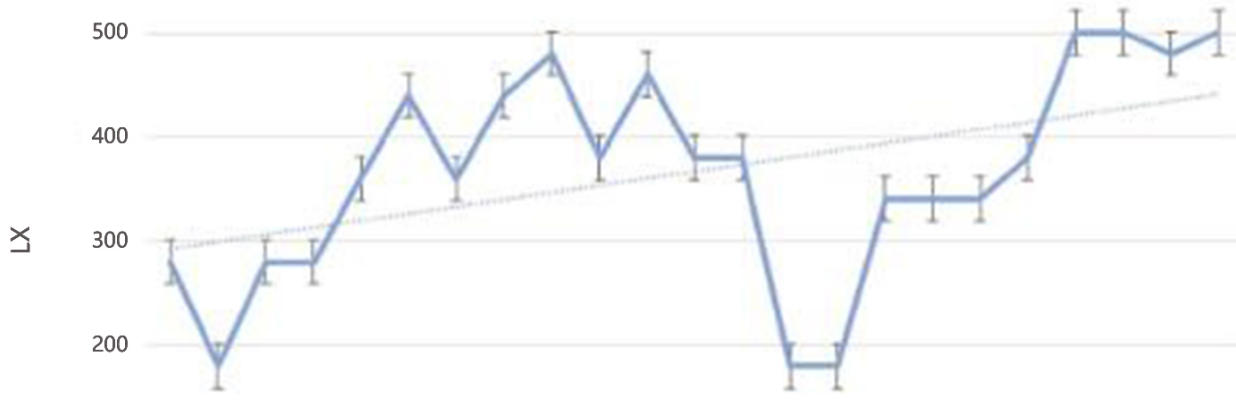

100

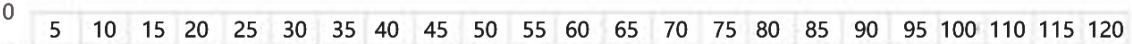

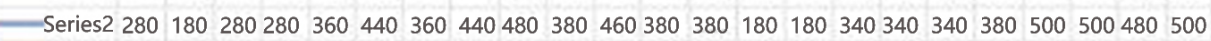

- Series2 Lineal(Series2)

Figure 13. Paraffin Candle (Graph) 
It can be seen that in the two trend lines of the two graphs, figures 12 and 13 are ascending, but that of the paraffin candle has a very steep slope.

To know the light intensity, we must use an equation [8]:

$$
E_{i x}=\frac{I_{c d}}{d_{m}^{2}}
$$

The calculation is made on the two means and we have,

$I_{\text {mean }(y 1)}=152.17 \cdot(0.5)^{2}=38.0425 \mathrm{~cd}$

$I_{\min (\mathrm{y} 1)}=40 \cdot(0.5)^{2}=10 \mathrm{~cd}$

$I_{\max (y 1)}=300 \cdot(0.5)^{2}=75 \mathrm{~cd}$
$I_{\text {mean }(\mathrm{y} 2)}=366.96 \cdot(0.5)^{2}=91.74 \mathrm{~cd}$

$I_{\min (\mathrm{y} 2)}=180 \cdot(0.5)^{2}=45 \mathrm{~cd}$

$I_{\max (\mathrm{y} 2)}=500 \cdot(0.5)^{2}=125 \mathrm{~cd}$

$10 \leq \mathrm{I}_{\mathrm{y} 1} \leq 7545 \leq \mathrm{I}_{\mathrm{y} 2} \leq 125$

As you can see the light intensity is also higher in the case of paraffin candle.

Data extracted from the Bulletin of Experimental Archeology referenced [9], tells us the average temperature of the marrow lamp with different wicks, for the wick called burlap $67.6^{\circ} \mathrm{C}$ and for the wick of fungus plaster $131.36{ }^{\circ} \mathrm{C}$ taken temperatures with a pyrometer. The temperature of a bonfire is average $800^{\circ} \mathrm{Celsius}$.

\section{Comparative}

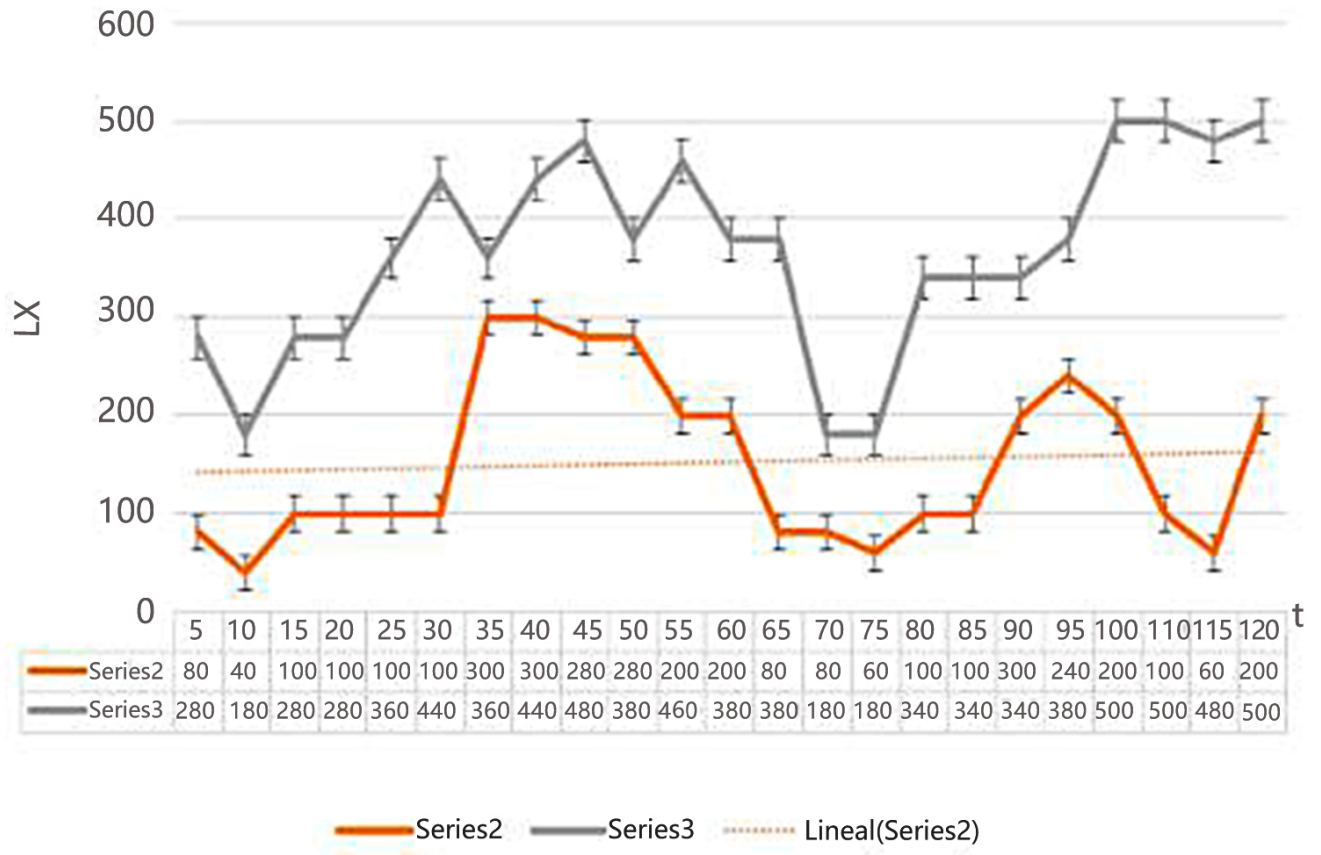

Figure 14. Comparative (Graph) 


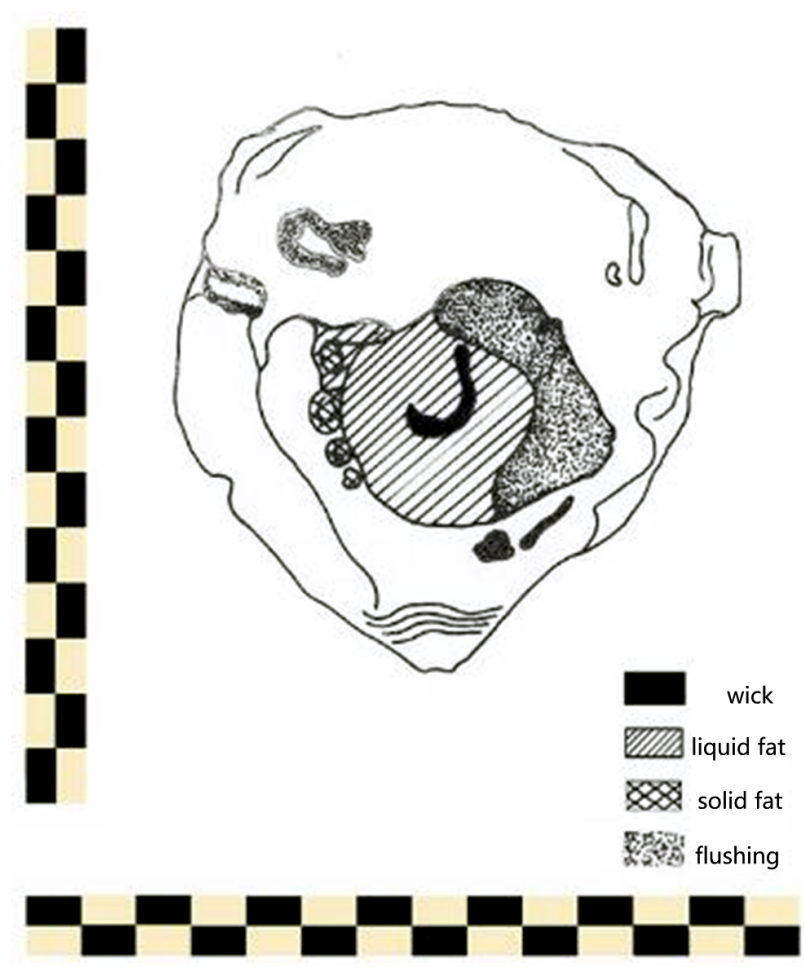

Figure 15. Archaeological drawing of the interpretation of the ancient lamp

According to the previous study, there is a relationship between the temperature of the fire and its luminosity, when the average temperature is high, the duration of the flame is prolonged, and there is greater luminosity. In summary, the temperature-time relationship is inversely proportional, and the temperature-luminosity ratio is directly proportional [9].

Once the experiment has been carried out with its measurements, the reproduction of the paleolithic lamp is analyzed. An archaeological drawing is made to study the results (figure 15).

In the legend of the archeological drawing we can see that despite reaching a lower temperature, than the flames with another type of fuel, it is seen that there is flushing, that is, that the oyster, which is the lamp holder, has changed of color by fire action.

It can be seen how the fat deposits, both liquid and solid, are arranged, the shape is homogeneous due to the density of the marrow.

In summary as for the results we have, that at least in the upper Paleolithic they had technology, especially about fire, a colder, more stable fire that does not cause smoke or consume too much oxygen. So, they could make these sculptural sets in blind cavities without leaving any trace of smoke.

\section{Discussion}

The theoretical results backed by archaeological evidence still wait to be expanded by new discoveries. From the two Venus relative to homo erectus (Berekhat Ram \& Tan-Tan Venus), and various engravings belonging to the same species, it follows that the origin of the art is erectus, not Neanderthal, or Cro-Mangon, although these last two species they present a good artistic quality in their works. These first results are contained within the creation cladogram.

The great complexity of Neanderthal paintings is recorded, as in the case of the Pasiega enigma, where the synthesis of the image tells us that this is not the first Paleolithic painting, in art we first copy nature, then interpret and Finally we create a symbolic language, the latter case is that of the Pasiega symbol. Therefore, from the advanced Neanderthal art and its technology it follows that the first art must be erectus.

The methods compared to other studies are the usual ones in archeology, although the vision and analysis comes from the field of aesthetics, because it is what is analyzed.

There are no preliminary studies on the origin of art in relation to hominid species. All there is a classification and dating of archaeological artifacts, and even interpretations, and not a logical sequence that corresponds to an aesthetic theory about the origin of art, this is intended to be the first.

\section{Conclusions}

The origin of Art is so ancient com the origin of humanity, it is the first human need. First art would be from Nature, a "serendipity", a beautiful natural object found by a hominid that gives it the necessary importance and that It becomes an aesthetic pre-object.

All the archaeological evidences classified in the cladogram of creation conclude that the first necessity as a human species is aesthetics, and as an art purpose. Outside the needs of the reptilian brain, the human needs something that is not apparently useful, but that fills the soul, art.

The description of the scientific, technical, and artistic knowledge of Paleolithic society, such as its fire technology, shows that the ancients were not so primitive. This is necessary to assess the paleolithic culture as current civilizations are valued, and not fall into topics that can alter reality.

\section{Acknowledgements}

I thank Ph. Doctor Valentín Villaverde for his support during my doctoral thesis and his advice, and for the updates and his dissemination of the latest Neanderthal discoveries.

I also thank my friend Ángel Flores for his vision to detect the pattern of the enigma of the Pasiega and its relationship with astronomy. 


\section{REFERENCES}

[1] Araceli Giménez Lorente. L’escultura al Paleolític. Lectura des d'una visió contemporània. "The sculpture in the Paleolitic. Reading from a contemporany vision”. PhD Thesis. UPV, 2004.

[2] Elias Canetti. Masa y Poder. Alianza Muchnik, pp. 12-13. Madrid, 1995.

[3] Francesco d'Errico, April Nowell. A New Look at the Berekhat Ram Figurine: Implications for the Origins of Symbolism. Cambridge Archaeological Journal/Volume 10/Issue 01/April, 123-167, 2000. Published online: 27 June 2001. Online available from http://journals.cambridge.org/ abstract_S0959774300000056

[4] Robert G. Bednarik. A Figurine from the African Acheulian. Current Anthropology. 408, 2003.

[5] Luc-Henri Fage- Néanderthal à Bruniquel. CNRS Images et Félis Production. Université de Bordeaux, 2016. Online available from https://lejournal.cnrs.fr/videos/bruniquel-lagrotte-qui-bouleverse-notre-vision-de-neandertal

[6] Sophie Verheyden, Jacques Jaubert. Découverte majeure à Bruniquel (vallée de l'Aveyron): l'homme de Néandertal, premier spéléo ou premier vandale? Eco Karst. 2016.

[7] Don's Maps.Resources for the study of Palaeolithic / Paleolithic European, Russian and Australian Archaeology / Archeology. Le Tuc d'Aubert. Online available from https://www.donsmaps.com/tucdaudoubert.html

[8] Begoña Soler Mayor. Fire Archaeology. Workshop. UV. 1999.

[9] Sophie A. De Beaune. Lampes et godets au paléolithique. XXIIIe supplément à Gallia Préhistoire Éditions du Centre National de la Recherche Scientifique, pp.126,127. París, 1987.

[10] Estefanía Pérez Martín, David Muñoz Domínguez. Los combustibles en las lámparas del Paleolítico superior. Boletín de Arqueología Experimental, 10 (2013-2015), pp.201, 204, 2006. 